\title{
O ENSINO DE SOLOS NO CURSO DE LICENCIATURA EM GEOGRAFIA: ANÁLISE CURRICULAR DO EXTREMO SUL DO RIO GRANDE DO SUL ${ }^{1}$
}

\author{
Gabriela Klering Dias ${ }^{(a)}$ Luis Eduardo Akiyoshi Sanches Suzuki ${ }^{(b)}$ Liz Cristiane Dias ${ }^{(c)}$
}

(a) Instituto de Ciências Humanas, Universidade Federal de Pelotas, gabikdiasgeo@gmail.com

(b) Departamento de Engenharia Hídrica, Universidade Federal de Pelotas, dusuzuki@ gmail.com

(c) Instituto de Ciências Humanas, Universidade Federal de Pelotas, lizcdias@gmail.com

EIXO: GEOGRAFIA FÍSICA: CURRÍCULO, FORMAÇÃO E PRÁTICAS DE ENSINO

\begin{abstract}
Resumo
Este trabalho discute as diferentes abordagens da Ciência do Solo e verifica se o conhecimento adquirido pelos formandos em Licenciatura em Geografia da UFPel atende ao previsto nos PCN's e nos livros didáticos do Ensino Fundamental - Anos Finais, especificamente a Coleção Projeto Araribá, disponíveis nas escolas de Pelotas/RS. Com base no previsto nesses documentos foram elencadas temáticas relacionados à Ciência do Solo abordadas no Ensino Fundamental. Elaborouse um questionário acerca dos solos, aplicado aos alunos. A partir dos questionários, os dados foram tabulados e analisados de forma descritiva. Este estudo pode constatar que tanto os PCN's Geografia e os livros didáticos para o Ensino Fundamental abordam de forma limitada o conhecimento sobre solos, assim como os dados obtidos do conhecimento dos graduandos pesquisados, possuindo lacunas, sendo restrito para o trabalho com ensino de solos, havendo uma demanda dos próprios alunos para a inclusão no curso de disciplinas sobre solos.
\end{abstract}

Palavras chave: Educação em solos; Parâmetros Curriculares Nacionais; Ensino de Geografia Física; Formação de Professores.

\section{Introdução}

O solo é um recurso natural indispensável para a vida na Terra. Ele é fonte de nutrientes para o desenvolvimento de plantas, suporte para construções civis, filtro ambiental e outras funções essenciais.

Apesar de sua vital importância, ele é pouco ou inadequadamente abordado nas escolas. No ensino superior, alguns cursos de graduação em Geografia não possuem ou possuem de forma insuficiente em seu currículo disciplinas voltadas para a área da Ciência do Solo.

Este trabalho pretendeu trazer para discussão as diferentes abordagens da Ciência do Solo nos distintos níveis de ensino (Fundamental, Médio e Graduação), buscando subsídios para auxiliar o ensino de Ciência

\footnotetext{
${ }^{1}$ Esse trabalho faz parte das pesquisas realizadas no Núcleo de Pesquisa em Ensino de Geografia Física e Temáticas Ambientais do Extremo Sul do Rio Grande do Sul (PEGFA - Extremo Sul) - Grupo de Pesquisa Espaços Sociais e Formação de Professores GESFOP/UFPel.
} 
do Solo nos cursos de graduação em Geografia, especialmente a licenciatura, dada a importância do solo na formação do professor e para a sociedade.

A Ciência do Solo e sua importância no ensino - É necessário o estudo do solo nas escolas, não apenas a sua formação e estruturas, mas também a necessidade de preservá-lo como fator fundamental para a existência da vida, para a extração de recursos, para a produção de alimentos e como local de morada das sociedades (VAZ; ANJOS, 2009).

De acordo com Silva; Ribeiro (2004) o estudo do solo, a aquisição e disseminação de informações sobre o papel que ele desempenha, e sua importância na vida do homem, são condições fundamentais para sua proteção e conservação, e uma garantia da manutenção de meio ambiente sadio e sustentável. No entanto, segundo os mesmo autores o espaço dedicado ao solo é frequentemente nulo ou relegado a um plano menor nos conteúdos de ensino nas escolas.

A partir de minicursos organizados com o propósito de contribuir com o processo de formação continuada dos docentes da rede pública dos anos finais do Ensino Fundamental e Ensino Médio, nas áreas de História e Geografia, Perusi; Sena (2012) concluíram que a educação em solos, dentro do contexto da educação ambiental inclusiva, pode contribuir para o desenvolvimento de habilidades dos alunos, das básicas às mais complexas, desde que mediada pelo professor devidamente preparado e subsidiado com materiais didáticos adequados.

O estudo do solo na Geografia é relevante ao considerar sua importância para o ambiente e para as atividades humanas, cabendo à ciência geográfica, sobretudo, conhecer a gênese, a distribuição espacial e as características do solo, visando o uso e a ocupação racional do espaço pelo ser humano. Nesse sentido, o conteúdo de solos deve ser trabalhado nas séries iniciais do Ensino Fundamental, para despertar na criança a relevância desse recurso para o ser humano e o ambiente. Nos anos seguintes da escola, o conhecimento sobre o assunto deverá ser aprofundado progressivamente, de forma que os alunos possam adquirir bases sobre a interrelação do solo com os demais elementos do meio, sua distribuição espacial, processo de formação, principais características e alguns cuidados necessários com manejo e conservação (PRATES, 2010).

Embora as pessoas tenham a preocupação ambiental como parte do seu cotidiano, a percepção do ambiente e seus componentes ainda é deficiente, especialmente no que se refere ao solo. Diante dessa deficiência da maioria das pessoas frente ao solo, a educação se faz ainda mais necessária, no sentido de se promover uma mudança de valores e atitudes (MUGGLER et al., 2004). 


\section{Metodologia}

Este trabalho contempla uma pesquisa documental (SEVERINO, 2007), tendo como fonte de pesquisa os Parâmetros Curriculares Nacionais (PCN's) e a coleção de livros didáticos "Projeto Araribá" do Ensino Fundamental Anos Finais ( $6^{\circ}$ a $9^{\circ}$ ano). Também foi utilizado como técnica de pesquisa o questionário com questões abertas, que de acordo com Severino (2007) é um conjunto de questões sistematizadas, com o objetivo de obter informações por parte dos pesquisados, na qual eles elaboram suas respostas com suas próprias palavras.

A partir dos PCN's para a Geografia e dos livros didáticos, foram elencados os assuntos abordados no Ensino Fundamental e Médio relacionados à Ciência do Solo. A partir destes assuntos, elaborou-se um questionário abordando questões sobre solos que foi aplicado aos alunos em fase de conclusão do curso de Licenciatura em Geografia da Universidade Federal de Pelotas (UFPel), no segundo semestre de 2015 e primeiro semestre de 2016. Os alunos não foram identificados nos questionários.

A finalidade do questionário foi avaliar se o conhecimento em Ciência do Solo dos alunos do curso de Licenciatura em Geografia da UFPel atende aos PCN's e os livros didáticos. A partir dos questionários, os dados foram tabulados e analisados. A análise feita nos questionários foi descritiva, com a finalidade de avaliar o conhecimento em Ciência do Solo destes alunos, sendo apresentada a seguir. Algumas respostas apresentadas pelos alunos foram trabalhadas de forma a torná-las mais apresentáveis, mas sem modificar seu entendimento e compreensão.

\section{Desenvolvimento e resultados}

\subsection{Eixos temáticos em Ciência do Solo nos PCN's e nos livros didáticos}

Os Parâmetros Curriculares Nacionais (PCN’s) para o terceiro ( $5^{\mathrm{a}}$ e $6^{\mathrm{a}}$ série) e quarto ciclo ( $7^{\mathrm{a}}$ e $8^{\mathrm{a}}$ série) indicam como tema transversal "meio ambiente" (BRASIL, 1998), e indicam no tema Sociedade e Meio Ambiente tratar da formação socioespacial, das novas territorialidades e temporalidades do mundo, abordar de forma ampla os processos que geram uma determinada ocupação do solo, as demandas por recursos naturais, o crescimento populacional e a urbanização, entre outros. Cita ainda compreender as relações com as diferentes paisagens vegetais e a zonalidade dos tipos de solos, para o terceiro ciclo, tratar os componentes da natureza nas suas especificidades, mas sem perder de vista que muitos dos seus mecanismos são interativos. Nesse sentido, torna-se essencial o ensino de solos dentro do tema transversal, buscando relacionar o clima e a vegetação, os solos e o relevo, ou ainda como clima, solos e 
relevo se interrelacionam. Em outro exemplo, o estudo dos solos onde determinados tipos de solos reagem aos modos de ocupação, ou ainda, discutir como ocorre a erosão, a desertificação, os deslizamentos de terra e suas relações com o desmatamento, a irrigação ou o uso excessivo dos solos.

Costa; Mesquita (2010) citam que o conteúdo sobre solos deve ser inserido nas séries iniciais do Ensino Fundamental, pois é nesta fase que a criança pode ser despertada sobre a relevância desse recurso para o ser humano e o ambiente, enquanto que nas séries seguintes, o conhecimento sobre o assunto deverá ser aprofundado progressivamente, de forma que o aluno possa adquirir bases sobre a interrelação do solo com os demais elementos do meio, sua distribuição espacial, processo de formação, principais características e alguns cuidados necessários com manejo e conservação.

Sobre o conteúdo desenvolvido no livro de Geografia do Projeto Araribá para o $6^{\circ}$ ano do Ensino Fundamental (DANELLI, 2007a), referente ao Programa Nacional do Livro Didático (PNLD) de 2011 a 2013, no tema 1 (Paisagem, espaço e lugar) da unidade 1 (A Geografia e a compreensão do mundo), a abordagem do solo pode ser qualificada e aprofundada, bem como utilizar termos mais adequados, quando se fala sobre a "destruição da vegetação" e "exploração do solo" no item "as paisagens transformadas". Pode-se utilizar termos técnicos associados aos termos utilizados no livro, como por exemplo: "lavar" os nutrientes do solo pode ser substituído por "lixiviar" e/ou "escoar"; "detritos" (fragmentos de rochas, solo) pode ser substituído por sedimentos. No tema 2 (O trabalho e a transformação do espaço geográfico) da unidade 1 (A Geografia e a compreensão do mundo), o solo pode ser abordado diretamente e intensamente neste tema, pois a divisão territorial do trabalho e as relações entre trabalho e paisagem envolvem o solo.

No tema 2 (Os processos de formação e transformação do relevo) da unidade 4 (Relevo e hidrografia), quando se fala sobre erosão, especialmente a acelerada, a pluvial e a eólica, o solo pode ser abordado diretamente, especialmente as fases do processo erosivo e de que forma a ação do ser humano pode influenciar neste processo. Até mesmo quando se fala sobre relevo, as características do solo, que muitas vezes definem seu uso, sofrem influência do mesmo.

Na unidade 6 (O campo e a cidade), o solo pode ser abordado de forma intensa no tema 1 (O espaço rural e suas paisagens), relacionando o solo com a tecnologia empregada, tamanho da propriedade rural e tipo de cultivo; no tema 2 (Problemas ambientais no campo), quando se fala sobre a degradação dos solos; uso de fertilizantes químicos e agrotóxicos e contaminação do solo e da água; impactos ambientais resultantes da irrigação. No tema 3 (A agricultura) da unidade 7 (Extrativismo e agropecuária), o solo também pode ser abordado de forma intensa e direta, quando se fala sobre as "condições naturais necessárias para o desenvolvimento da agricultura" e os "tipos de agricultura" (subsistência e comercial). Percebe-se que no 
conteúdo para o $6^{\circ}$ ano o conhecimento sobre o solo é essencial, e um conhecimento mais aprofundado permite fazer relações que possibilitam um olhar mais abrangente e aberto sobre a Geografia e o mundo.

Oliveira (2014) cita que os livros didáticos apresentam conceitos muito superficiais, ultrapassados e incorretos, pois a deficiência também está presente na formação dos professores e autores de livros didáticos sobre o tema ciência do solo. Por outro lado Lima (2005) cita que apesar da importância do solo para o ser humano, o ensino deste tema na educação fundamental pode ser considerado de qualidade inferior à desejada, devido a um conjunto de fatores educacionais, sociais e econômicos, enquanto que o conteúdo solos, embora abordado nos PCN's e nos currículos escolares, apresenta problemas em sua implantação, por causa de falhas nos livros didáticos e na formação básica e continuada dos professores.

A respeito do conteúdo abordado no livro de Geografia do Projeto Araribá para $07^{\circ}$ ano do ensino fundamental (DANELLI, 2007b), referente ao Programa Nacional do Livro Didático (PNLD) de 2011 a 2013, no tema 4 (Problemas sociais e ambientais nas cidades) da unidade 3 (Industrialização e urbanização do Brasil), há um pequeno apontamento sobre a ocupação de casas em áreas de risco, como vertentes de morros ou às margens de rios. Nesse caso, a discussão pode ser intensificada a respeito de desmoronamentos associados a solos rasos nas encostas, e o assoreamento de rios devido o aporte de sedimentos e a possibilidade de seu extravasamento da calha com maior frequência. O livro ainda aborda as regiões do Brasil (Norte, Nordeste, Sudeste, Sul, Centro-Oeste), e nelas ressalta-se a questão agrícola, o povoamento, a ocupação do espaço, problemas com erosão, mas pouco se associa o solo nestas questões.

Na região Norte o livro aponta sobre "a importância da floresta Amazônica" e cita que seus solos são bastante pobres em nutrientes, mas como a floresta é muito densa, forma-se sobre o solo uma camada de folhas, galhos e troncos, que se decompõem formando os nutrientes necessários para a manutenção da floresta. Neste caso é interessante a explanação sobre a ciclagem de nutrientes e manutenção da floresta, por exemplo. Além disso, o livro cita ainda para esta região a degradação dos solos pela erosão hídrica em áreas onde a floresta é derrubada para implantação da agropecuária.

Para a região Nordeste o livro aponta a questão do assoreamento do rio São Francisco pelo seu uso intensivo, e apresenta a definição de assoreamento como sendo o "acúmulo de detritos, transportados pelas águas, no leito de um rio”. Nesse caso pode-se inserir na discussão questões como erosão hídrica que ocorre nas áreas agrícolas e que aportam sedimentos nos rios e riscos de contaminação da água, a erosão que ocorre nas margens dos rios desprotegidas de vegetação marginal, e isso permite incluir questões como legislação ambiental e a importância da vegetação nativa nas margens dos rios. Sobre a região Sudeste, o livro aborda "os processos erosivos e a ação humana". Na região Sul o livro fala um pouco 
sobre a agricultura nesta região, mas em nenhum momento ele cita o solo. Na região Centro-Oeste o livro fala sobe a vegetação de cerrado e o solo, assim como a questão da produção agrícola.

A respeito do conteúdo abordado no livro de Geografia do Projeto Araribá para o $8^{\circ}$ ano do Ensino Fundamental (DANELLI, 2007c), referente ao Programa Nacional do Livro Didático (PNLD) de 2011 a 2013, o solo é abordado de forma incipiente, apenas quando se fala da vegetação da América no tema 4 (Clima e vegetação da América) da unidade 3 (O continente americano). O livro cita a importância de se conhecer a vegetação original, pois ela é interdependente de outros elementos da natureza, como o solo.

Quando o livro cita a vegetação Tundra, informa que o solo fica coberto por gelo em alguns meses do ano. Nas Florestas Tropicais e Equatoriais (Pluviais) o livro cita que "os solos de algumas Florestas Pluviais são pouco férteis, mas em sua parte superior apresentam uma camada muito rica de material orgânico conhecido como húmus". No tema 2 (Atividades do setor primário na América) da unidade 4 (A população e a economia da América), a questão da agricultura é citada na América Anlo-Saxônica e na América Latina, e o solo é referido especialmente na questão da correção da sua fertilidade. Percebe-se que embora pouco explorada a Ciência do Solo neste livro, nota-se o conhecimento fundamental para explorar alguns conhecimentos do solo como o húmus e sua formação, bem como seu efeito nas características físicas, químicas e biológicas do solo, assim como a necessidade de se abordar a ciclagem de nutrientes para manutenção das florestas. Há ainda a possibilidade de se discutir questões como o congelamento dos solos, situação que não ocorre no Brasil, por exemplo, mas é citado no livro quando se fala sobre a Tundra.

Em relação ao conteúdo abordado no livro de Geografia do Projeto Araribá para o $9^{\circ}$ ano do ensino fundamental (DANELLI, 2007d), referente ao Programa Nacional do Livro Didático (PNLD) de 2011 a 2013, em duas situações o solo poderia ser abordado, quando se fala sobre agricultura e sobre as questões ambientais. Por exemplo, no tema 2 (Globalização e meio ambiente) da unidade 2 (Globalização e organizações mundiais), quando se fala sobre os problemas ambientais do século XXI, não se pode deixar de relatar a degradação dos solos, bem como o desmatamento associado ao plantio de novas áreas agrícolas, tanto em solos adequados ou não para a agricultura.

Uma abordagem semelhante pode ser feita no tema 1 (Quadro natural e problemas ambientais) da unidade 3 (O continente europeu). Quando se aborda a agricultura na Europa (tema 3 - A economia européia, da unidade 3 - O continente europeu), na Ásia (tema 3 - A economia do continente asiático, da unidade 5 O continente asiático), na África (tema 2 - A economia africana, da unidade 7 - O continente africano), também pode-se inserir na discussão a questão do solo, pois a agricultura embora tenha relação direta com 
o clima, também influencia em questões como tipo de cultura, irrigação e mecanização. No conteúdo do $9^{\circ}$ ano, percebe-se que o solo pode ser trabalhado relacionando-o com a agricultura e com a sua degradação.

Em relação aos livros de Geografia do Projeto Araribá do $6^{\circ}$ ao $9^{\circ}$ ano do ensino fundamental referente ao Programa Nacional do Livro Didático (PNLD) de 2014 a 2016 (VEDOVATE, 2010a, b, c, d), percebeu-se que não houve alterações significativas, principalmente nas questões relacionadas à abordagem do solo.

\subsection{Conhecimento em Ciência do Solo dos alunos do curso de Licenciatura em Geografia}

Os questionários foram aplicados em dois momentos aos alunos do curso de Licenciatura: em novembro de 2015, aos alunos com previsão de formatura no segundo semestre de 2016, e em junho de 2016, aos mesmos alunos durante o sétimo semestre. Os questionários foram respondidos por 35 alunos do curso de Licenciatura em Geografia, sendo que destes alunos, um deles também cursa Bacharelado em Geografia. A idade dos alunos variou entre 21 e 50 anos, com distribuição dos alunos nas faixas de 20,30 e 40 anos de idade. Destes, 19 eram do sexo masculino e 16 do sexo feminino.

O ano de ingresso no curso de Licenciatura abrangeu de 2006 a 2014, sendo um aluno ingressante em 2006, e um em 2007, nenhum ingressante em 2008, dois ingressantes em 2009, três ingressantes em 2010, seis ingressantes em 2011, doze em 2012, seis ingressantes em 2013 e um em 2014. Três alunos não informaram o ano de ingresso, e o aluno que também cursa Bacharelado ingressou em 2009.

Questionados sobre “O que é solo?", seis alunos não responderam a questão, enquanto dez alunos definiram solo como camada ou cobertura superficial ou externa da crosta terrestre; material ou camada que cobre a superfície terrestre, e outros dois alunos incluíram na resposta anterior o solo como sustento a vários tipos de vegetação; onde se desenvolve atividades agrícolas e extrativismo. Outros três alunos definiram solo como fragmentos de rochas; rocha em decomposição.

Outras definições de solo foram apontadas pelos alunos como: local ou porção composto principalmente por resíduos orgânicos e minerais; um conjunto de matéria orgânica e sedimentos; material resultante de um processo de decomposição mineralógica; partículas rochosas, de granulometrias variadas e composição mineral também distintas; material em superfície, detentor de características arenosas, argilosas e outras, dependendo do material rochoso que impõe o seu entorno; resultado da transformação física e química das rochas que, ao ser somado com material orgânico, oferece condições para ser usado em diversas áreas com diversas funções.

Algumas respostas apresentaram dificuldade em definir o solo: partículas de terra e minerais; camada que reveste o relevo da terra; matéria orgânica acumulada; terra onde se fixam os vegetais; sedimentos 
acomodados na crosta terrestre; concentração de detritos compactados ricos em minerais; camada do relevo terrestre; a terra e o seu uso. Em algumas respostas ficou evidente a dificuldade em diferenciar solo e terra.

Sobre “Como ocorre a formação do solo?", dois alunos não responderam, enquanto 14 alunos apontaram como o desgaste e/ou decomposição e/ou fragmentação e/ou intemperismo e/ou erosão e/ou transformação das rochas. Dois alunos indicaram que o solo é formado a partir da sedimentação das rochas. Outras respostas apresentaram dificuldade em apontar como ocorre a formação do solo: compactação de matéria orgânica e ou sedimentos; desgaste, erosão dos planaltos; deposição com a ocorrência da chuva e ventos que levam partículas diversas de um lugar para outro; a partir de um conjunto de sedimentos; através da concentração de diversos elementos que se acumulam dos mais variados eventos naturais e não naturais; ocorre com o acúmulo de materiais.

Sobre “O que é erosão?", apenas dois alunos não responderam, enquanto 15 alunos indicaram erosão como sendo a degradação e/ou desgaste do solo e/ou da rocha. Outras respostas também foram relacionadas, algumas com certa dificuldade em definir erosão: é a "deslização" que ocorre através do intemperismo; é o processo de deslocamento que uma rocha ou solo sofre com efeito da água, vento ou sol; é o processo de desgaste e transporte de sedimentos; é o processo de intemperismo químico e físico; processo de desgaste deste solo, onde acaba sofrendo com mais intensidade diversos processos de desgaste; degradação do solo; é o desgaste de rochas ou solos causando fendas e sedimentação; arraste de camadas do solo através dos ventos e das chuvas; é o desgaste físico, químico e biológico que o solo sofre alterando assim suas características; processo de intemperismo físico, químico e biológico, ocorridos na natureza; perda de nutrientes do solo; processo de desagregação das rochas; fissuras que são abertas no solo; é a "deteriorização" de formações rochosas (de variados tipos) através do intemperismo químico e físico; são fragmentos que se deslocam por motivos como água, vento, pressão; carreamento da porção superficial de solo por ação da água, vento e/ou degelo; é o mau uso da terra.

Se os alunos haviam cursado alguma(s) disciplina(s) específica(s) sobre solos, 19 alunos responderam não, enquanto 12 alunos apontaram Geologia e sete responderam Geomorfologia, embora para ambas as disciplinas os alunos indicaram que havia pouco conteúdo sobre solos ou apenas alguns aspectos básicos.

Questionados sobre a “importância da(s) disciplina(s) de solos na sua formação?", um aluno não respondeu enquanto 31 alunos consideram importante, com algumas justificativas: é extremamente importante, pois como um Geógrafo não temos formação adequada; ter um maior entendimento do uso do solo e da ocupação do mesmo; é muito importante, pois é uma ciência que está atrelada à Geografia; é importante justamente na compreensão não só de um movimento constante deste ciclo geológico, mas 
principalmente na sua importância na produção de alimentos; devemos ter um conhecimento de tudo que pudermos no que diz respeito ao nosso objeto de estudo que é a Geografia; tal disciplina é de extrema importância para a compreensão da dinâmica geoespacial em geral, tais como: formação da terra, sistemas de produção agrícola, distribuição de renda, etc; de grande relevância, pois o geógrafo, para poder compreender dados processos e fenômenos, necessita desse tipo de conhecimento específico.

Sobre a questão: "Você se sente preparado para trabalhar com o tema Ciência do Solo?", apenas um aluno afirmou estar preparado para trabalhar com o tema, enquanto 34 alunos responderam "não", com algumas justificativas: não pois tive poucos ensinamentos sobre solo no curso de Geografia; teria que aprofundar o assunto para ministrar aulas; não, de forma alguma, o curso de licenciatura não oferece uma disciplina para que o conhecimento seja aprofundado.

\section{Considerações Finais}

Os Parâmetros Curriculares Nacionais e os livros didáticos para o Ensino Fundamental, mesmo que de forma superficial abordam o conhecimento sobre solos, explicitamente questões como erosão, uso e manejo do solo, degradação do solo, fertilidade e o processo de arenização. Contudo, esta abordagem não explora a interdisciplinaridade e as relações do solo com outros fatores da natureza, além das questões sociais e econômicas globais.

De acordo com Oliveira (2014) os livros didáticos apresentam conceitos muito superficiais sobre solos, ultrapassados e incorretos, pois a deficiência também ocorre na formação dos professores e de autores de livros didáticos sobre o tema solo.

Essa pesquisa corrobora nesse sentido aos demonstrar a dificuldade dos futuros professores em trabalhar com essa temática e, ao considerar as limitações de muitos livros didáticos sobre o conteúdo solos, as universidades possuem importante papel na disseminação desse conhecimento nos cursos de formação de professores.

E bem como assim afirma SILVA e RIBEIRO (2004) na produção de material que possa ser utilizado por professores dos ciclos fundamentais. No entanto, este material deve ser claro e acessível, visualizando o tema "solo" como um conteúdo transversal, e estabelecendo sua relação principalmente com as Ciências Naturais e a Geografia, adequado à realidade dos solos brasileiros, com linguagem acessível e ao mesmo tempo correta tecnicamente.

Ao pensar na Geografia Escolar e na importância do tema solos dentro dos conteúdos, deve-se considerar a Educação Geográfica, sendo uma das possibilidades de se pensar um ensino voltado ao estímulo de 
ações que mobilizem o aluno a construção do conhecimento. Pensar o ensino possibilita criar condições para que o aluno compreenda os fenômenos geográficos que ocorrem a sua volta (SACRAMENO; FALCONI, 2011).

Dentro dessa perspectiva os autores destacam que no ensino sobre os solos, não há a possibilidade de simplesmente "passar" o conteúdo, mas deve-se dar significados a eles e organizá-los para que se destaque e mostre que essa discussão está dentro de outros conteúdos de Geografia como urbanização, agricultura, indústria dentre outros.

As Instituições de Ensino Superior (IES) podem auxiliar os professores do Ensino Fundamental a partir de projetos como por exemplo o Programa Institucional de Bolsas de Iniciação à Docência (PIBID) a melhorar o ensino de solos a partir do repensar a formação dos professores, uma vez que o conhecimento dos alunos graduandos em Licenciatura em Geografia carece de aprofundamento, uma vez que apresentase descontextualizado e com lacunas, o que prejudica ainda mais o trabalho com o ensino de solos no Ensino Fundamental e Médio, havendo uma demanda requisitada dos próprios alunos para a inclusão no curso de uma ou mais disciplinas específicas sobre a ciência de solos.

\section{REFERÊNCIAS}

BRASIL. SECRETARIA DE EDUCAÇÃO FUNDAMENTAL. Parâmetros curriculares nacionais: geografia /Secretaria de Educação Fundamental. Brasília: MEC/SEF, 1998.

MINISTÉRIO DA EDUCAÇÃO. Instituições de ensino superior e cursos cadastrados. Disponível em: <http://emec.mec.gov.br/>. Acesso em: 4 mar. 2017.

MUGGleR, C.C.; ALMEIDA, S.; MOL, M.J.L.; FRANCO, P.R.C.; MONTEIRO, D.E.J. Solos e educação ambiental: experiência com alunos do ensino fundamental na zona rural de Viçosa, MG. In: CONGRESSO BRASILEIRO DE EXTENSÃO UNIVERSITÁRIA, 2, Belo Horizonte, 2004, Anais 2004. Belo Horizonte, 2004. (CD-ROM)

PERUSI, M.C.; SENA, C.C.R.G. Educação em solos, educação ambiental inclusiva e formação continuada de professores: múltiplos aspectos do saber geográfico. Entre-Lugar, n. 6, p. 153-164, 2012.

PRATES, R. Análise das abordagens e discussões do conteúdo de pedologia nos livros didáticos de Geografia. 2010. 85f. Dissertação (Mestrado em Educação Agrícola). Universidade Federal Rural do Rio de Janeiro, Seropédica.

SEVERINO, A.J. Metodologia do trabalho científico. 23. ed. ver. e atual. São Paulo: Cortez, 2007.

SILVA, A.C.; RIBEIRO, A.L.S. A disciplina pedologia ministrada nos cursos de geografia em diversas cidades maranhenses por meio do PROCAD. Geografia, v. 13, n. 1, p. 143-150, 2004. 304p.

SUZUKI, Luis Eduardo Akiyoshi Sanches. Ensino de solos nos diferentes níveis de educação em Geografia: O conhecimento de solos dos estudantes de graduação em Geografia da UFPel. 2016. 48f. Trabalho de Conclusão de Curso (Licenciatura em Geografia) - Instituto de Ciências Humanas, Universidade Federal de Pelotas, Pelotas, 2016. 


$\begin{aligned} & \text { XVII Simpósio Brasileiro } \\ & \text { de Geografia Fisica Aplicada }\end{aligned}$
$\begin{aligned} & \text { I Congresso Nacional } \\ & \text { de Geografia Física }\end{aligned}$

VAZ, A.J.; ANJOS, R.M. Como trabalhar a educação ambiental através do estudo do solo em aulas de Geografia. In: ENCONTRO NACIONAL DE PRÁTICA DE ENSINO EM GEOGRAFIA, 10, Porto Alegre, 2009, Anais 2009, Porto Alegre, 2009. 14p. 